\title{
Comparison of body composition methods in overweight and obese Brazilian women
}

\author{
Comparação de métodos da composição corporal em \\ mulheres brasileiras com sobrepeso e obesidade
}

Valeria Bender Braulio', Valéria Cristina Soares Furtado², Maria das Graças Silveira', Maria Helena Fonseca', José Egídio Oliveira'

${ }^{1}$ Divisão de Metabolismo e Nutrição, Faculdade de Medicina, Universidade Federal do Rio de Janeiro (UFRJ), Rio de Janeiro, RJ, Brazil ${ }^{2}$ Departamento de Nutrição Aplicada, Escola de Nutrição, Universidade Federal do Estado do Rio de Janeiro (Unirio), Rio de Janeiro, RJ, Brazil

\author{
Correspondence to: \\ Valeria Bender Braulio \\ Rua Professor Rodolpho Paulo \\ Rocco, 255, $9^{\circ}$ andar, \\ sala 9E-14, Ilha do Fundão \\ 21941-913 - Rio de Janeiro, RJ, \\ Brazil \\ vbender2001@yahoo.com
}

Received on Nov/26/2009 Accepted on Mar/2/2010

\begin{abstract}
Objective:The purpose of this study was to compare skinfold thickness (SKF) and bioelectrical impedance analysis (BIA) of body composition using three different equations against dual-energy X-ray absorptiometry (DXA) in overweight and obese Brazilian women. Subjects and methods: Thirty-four women (age $43.8 \pm 10.9$ years; body mass index [BMI] $32.1 \pm 4.3 \mathrm{~kg} / \mathrm{m}^{2}$ ) had percentage body fat (BF\%), fat mass (FM) and fat-free mass (FFM) estimated by DXA, SKF and BIA (BIA-man: manufacturer's equation; and predictive obesity-specific equations of Segal and of Gray). Regression analysis, Bland-Altman plot analysis and intra-class correlation coefficient (ICC) were used to compare methods. Results: Absolute agreement between DXA and BIA-man was poor for all measures of body composition (BF\% $-6.8 \% \pm 3.7 \%$, FM $-3.1 \pm 3.6 \mathrm{~kg}$, FFM $5.7 \pm 2.8 \mathrm{~kg}$ ). BIA-Segal equation showed good absolute agreement with DXA for BF\% $(1.5 \% \pm 1.5 \%)$, FM $(1.0 \pm 3.2 \mathrm{~kg})$ and FFM $(1.5 \pm 2.6 \mathrm{~kg})$, albeit the limits of agreement were wide. BIA-Gray equation showed good absolute agreement with DXA for FM $(2.3 \pm 4.1 \mathrm{~kg})$, and smaller biases for $\mathrm{BF} \%(0.05 \% \pm 4.4 \%)$ and FFM $(0.2 \pm 2.9 \mathrm{~kg})$, although wide limits of agreement. BIA-Gray and DXA showed the highest ICC among the pairs of methods. A good absolute agreement was observed between DXA and SKF for BF\% $(-2.3 \% \pm 5.8 \%), F M(0.09 \pm 4.7 \mathrm{~kg})$, and FFM $(2.4 \pm 4.4 \mathrm{~kg})$, although limits of agreement were wider and ICC between DXA and SKF for BF\% indicated poor degree of reproducibility. Conclusion: These findings show that both BIA-Segal and BIA-Gray equations are suitable for BF\%, FM and FFM estimations in overweight and obese women. Arq Bras Endocrinol Metab. 2010;54(4):398-405

Keywords

Absorptiometry, photon; electric impedance; skinfold thickness; body composition; obesity; overweight
\end{abstract}

\section{RESUMO}

Objetivo: Verificar a concordância dos métodos de impedância bioelétrica (BIA) usando três equações diferentes, e medida das pregas cutâneas (PC) com absorciometria de raios- $X$ de dupla energia (DEXA), para análise da composição corporal de mulheres com sobrepeso e obesidade. Sujeitos e métodos: Em 34 mulheres (43,8 \pm 10.9 anos; índice de massa corporal [IMC] $\left.32,1 \pm 4,3 \mathrm{~kg} / \mathrm{m}^{2}\right)$ foram avaliados: percentual de gordura total (\%GT), massa gorda (MG) e massa magra (MM) por DEXA, PC, BIA-Fab (equação do fabricante), BIA-Segal e BIA-Gray (equações para obesidade). Foram utilizados: análise de regressão, método de Bland-Altman e coeficiente de correlação intraclasse (CCI). Resultados: A concordância absoluta entre DEXA e BIA-Fab foi fraca para todas as medidas (BF\% - $6,8 \%$

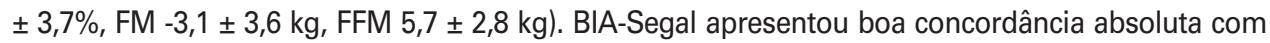
DEXA para \%GT $(1,5 \% \pm 1,5 \%)$, MG $(1,0 \pm 3,2 \mathrm{~kg})$ e MM $(1,5 \pm 2,6 \mathrm{~kg})$, mas com amplos limites de concordância. BIA-Gray teve boa concordância absoluta com DEXA para $M G(2,3 \pm 4,1 \mathrm{~kg})$ e pequenos vieses para $\% \mathrm{GT}(0,05 \% \pm 4,4 \%)$ e $\mathrm{MM}(0,2 \pm 2,9 \mathrm{~kg})$, mas com amplos limites de concordância. BIA-Gray e DEXA tiveram maior $\mathrm{CCl}$ entre métodos. Houve boa concordância absoluta entre DEXA e PC para $\% \mathrm{GT}(-2,3 \% \pm 5,8 \%), \mathrm{MG}(0,09 \pm 4,7 \mathrm{~kg})$ e MM $(2,4 \pm 4,4 \mathrm{~kg})$, mas com amplos limites de concordância e pouca reprodutibilidade no $\mathrm{CCl}$, entre DEXA e PC para \%GT. Conclusão: A BIA, utilizando equação específica para obesidade, foi o método que melhor concordou com DEXA, para estimar \%GT, MG e MM em mulheres com sobrepeso e obesidade. Arq Bras Endocrinol Metab. 2010;54(4):398-405

Descritores

Absorciometria de fóton; impedância elétrica; pregas cutâneas; composição corporal; obesidade, sobrepeso 


\section{INTRODUCTION}

$\mathrm{O}$

verweight and obesity are increasing at alarming rates throughout the world $(1,2)$. Obesity is characterized by an excessive amount of body fat, which is the main cause for health hazards such as hypertension, diabetes, and heart disease $(3,4)$. In addition, the preservation of fat-free mass is a target in the treatment of this disease (5). Hence, in this context it is important to identify a simple, reliable, non-invasive and cost-effective technique for body composition assessment.

There is no direct method for measuring adiposity, and the most frequently used indirect methods are dual-energy X-ray absorptiometry (DXA), bioelectrical impedance analysis (BIA) and anthropometry. DXA is considered to be a valid and reliable reference method for body composition assessment (6). DXA measures three body compartments: fat mass, lean body mass, and bone content. However, the use of DXA is limited in some situations due to the cost of the equipment, the need for training an operator, and lack of portability, all of which limit its application in diverse facilities, including clinic rooms and private health centers (7). Consequently, there is a need for simpler, more accurate and reliable, as well as less expensive and less invasive body composition measuring than the DXA technique.

Bioelectrical impedance analysis and skinfold thickness (SKF) are non-invasive methods for body composition assessment that can be readily performed by trained operators in most facilities since these equipment are easily transported. They also have the advantage of being relatively quick to perform (8).

BIA is based on the conduction of an electrical current through the body (9). Using the assumption of a conductive material constant resistance, and estimating the length of the conductive path from an individual's height, total body water can be calculated from impedance measuring through the flow of a small current. Body composition can then be estimated assuming that total body water constitutes a fixed percentage of lean mass (usually 73\%). Specific prediction equations have been developed to evaluate body composition from height, weight, and impedance (10). As BIA accuracy mainly depends on the equation used, several researchers have developed specific equations to use with obese adult populations (11-14). However, no firm conclusions can be drawn regarding the predictability of those equations.

Skinfold thickness is a long established method for determining body fat. The sum of four SKF provides an estimation of the fat mass, and subtracting it from total body weight, fat-free mass is valuated (15). Although with altered fat distribution conditions the method has been questioned, and also due to inter-observer errors, in clinical facilities, it has been the most simple and inexpensive technique available, and its applicability is possible in a large number of subjects (16).

Validity of body composition measurements is scarce for Brazilian obese people data $(17,18)$. Therefore, the current study worked with SKF and BIA for body composition assessment in overweight and obese Brazilian women. BIA was assessed using standard and obesity-specific equations. Both methods were compared with DXA as a reference method to verify the degree of similarity among techniques.

\section{SUBJECTS AND METHODS}

\section{Subjects}

Thirty-four overweight and obese Brazilian women with mean body mass index (BMI) $32.1 \pm 4.3 \mathrm{~kg} / \mathrm{m}^{2}$ (range $25.0-39.7 \mathrm{~kg} / \mathrm{m}^{2}$ ), mean age $43.8 \pm 10.9$ years participated in this study. Subjects were outpatients beginning a hospital weight-loss program. Exclusion criteria included pregnancy, hypothyroidism, and body weight over $120 \mathrm{~kg}$, anterior-posterior abdominal diameter exceeding $30 \mathrm{~cm}$, and use of medication influencing fluid balance and metabolism.

Informed consent which was approved by the local research ethics committee of the Hospital of Federal University of Rio de Janeiro, was obtained from all participants before entering the study.

\section{Protocol}

Subjects were studied four hours after their last meal, and after they had emptied their bladders before their body weight and height were recorded. Height was measured to the nearest $0.1 \mathrm{~cm}$ using a Sanny ${ }^{\circledR}$ stadiometer, and subjects stood up erect without shoes. Weight was measured to the nearest $0.1 \mathrm{~kg}$ using Welmy ${ }^{\circledR}$ scale. The scale was calibrated prior to each test. BMI was calculated as body weight (in $\mathrm{kg}$ ) divided by squared height (in meters).

Body composition measurements to determine fatfree mass (FFM), fat mass (FM), and percentage body fat $(\mathrm{BF} \%)$ were made using each of the following three methods: 
1. DXA scanning (Lunar DPX-IQ, version 4.7e, Lunar Radiation Corporation, Madison, WI, USA), according to standardized procedures recommended by the manufacturer. Calibration using the manufacturer's phantom was performed on each scanning day. Subjects reclined on a flat couch, dressed in light clothing, and wore no metal objects. The whole body was scanned. Scan duration typically ranged from 10 to $30 \mathrm{~min}$ depending on the subject's size, with radiation dose for a scan being approximately $0.5 \mu \mathrm{Sv}$. The results were presented in $\mathrm{kg}$ for FFM, FM, and in \% for BF\%. FFM was calculated using the sum of lean tissue mass and bone mineral content estimations for each subject. DXA was the reference method.

2. BIA was undertaken with a tetrapolar bioanalyzer device (Model 310, Biodynamics Corp., Seattle, WA - USA). Measurements were undertaken as previously described (9) by a single trained observer. Subjects reclined on a flat couch, with limbs not touching each other. Electrodes were placed on the right side of the body between the distal prominences of the radius and ulna; the distal end of the third metacarpal; between the median and lateral malleoli at the ankle; and at the distal end of the third metatarsal. FFM, FM and BF\% were calculated from the measurements of resistance made at $50 \mathrm{kHz}$ using the formula provided by the instrument manufacturer (BIA-man). In addition, the resistance directly read from the impedance device was considered along with height, weight, and age in two obesity-specific equations published by Segal and cols. (BIA-Segal) (13) and Gray and cols. (BIA-Gray) (11).

3. SKF measurements were performed by a single observer at four sites (triceps, biceps, subscapular and suprailiac) according to standard techniques. Skinfold measurements were performed on the body's right side with a Lange skinfold caliper (Cambridge Scientific Instruments, Cambridge, MD, USA). Three sets of measurements were averaged for each site. Body density was calculated from the sum of the four skinfold measurements according to Durnin and Wormersley (15), and BF\% was then calculated by Siri's equation (19). FFM (in $\mathrm{kg}$ ) was calculated subtracting body fat from total body weight.

\section{Statistical analysis}

Values are reported in the text as mean \pm standard deviation (SD). Statistical analysis were performed using SPSS version 13.0 (SPSS, Inc., Chicago, IL), and MedCalc version 9.6.4.0 (MedCalc Software, Mariakerke, Belgium). One-way ANOVA was used to compare di- fferences among body composition values determined using different techniques. When ANOVA showed a statistically significant mean effect, Bonferroni's test was used to determine differences among means. Regression analysis was used to determine the level of relative agreement among different techniques. BlandAltman analysis (20) was used to determine absolute limits of agreement between body composition variables assessed by BIA and SKF against DXA. The intra-class correlation coefficient (ICC) was used to test the reproducibility of $\mathrm{BF} \%, \mathrm{FM}$ and FFM measured by BIA-man, BIA-Gray and SKF compared to DXA. (21) Values of ICC below 0.4 were considered as an indication of poor reproducibility, values between 0.4 and 0.7 , medium-term reproducibility and values above 0.7 , good reproducibility. Statistical significance was considered when $\mathrm{p}<0.05$.

\section{RESULTS}

As can be seen in table 1, BIA-man results underestimated $\mathrm{BF} \%$ and overestimated FFM when compared with DXA, whereas no difference was observed between mean BF\% and FFM assessed by BIA-Segal, BIA-Gray and SFK, and DXA. Regarding FM measurements, no differences were found between the four techniques compared with DXA.

There was a good relative agreement between DXA and all assessments of body composition using BIAman, BIA-Segal, Bia-Gray, and SKF, except for BF\% evaluated by SKF (Table 2). In absolute terms, BIAman results underestimated $\mathrm{BF} \%$ by $6.8 \%$, and $\mathrm{FM}$ by $3.1 \mathrm{~kg}$, and overestimated FFM by $5.7 \mathrm{~kg}$, when compared with DXA, with wide limits of agreement for each variable (Table 2; Figure 1). BIA-Segal results overestimated BF\%, FM and FFM by $1.5 \%, 1.0 \mathrm{~kg}$ and $1.5 \mathrm{~kg}$, respectively. Even though this indicates that, on average, there was good absolute agreement between BIA-Segal and DXA for the three body composition measurements, the limits of agreement were wide for each variable (Table 2; Figure 2). There was a very good absolute agreement for measured values between DXA and BIA-Gray for BF\% and FFM, although BIAGray overestimated FM by $2.3 \mathrm{~kg}$. This indicates that, on average, there was good absolute agreement between BIA-Gray and DXA for all measures of body composition, albeit the limits of agreement were wide for each variable (Table 2; Figure 3). DXA and SKF demonstrated good absolute agreement for FM values. However, 
SKF overestimated FFM by $2.4 \mathrm{~kg}$, and underestimated $\mathrm{BF} \%$ by $2.3 \%$. There was, on average, good absolute agreement between SKF and DXA for all measures of body composition with wider limits of agreement for each variable (Table 2; Figure 4).

ICC results were indicative of good reproducibility between BIA-man and DXA for FM (0.791), BIA-Segal and DXA for FM (0.897) and FFM (0.784), BIAGray and DXA for BF\% (0.706), FM (0.833) and FFM (0.812), and between SKF and DXA for FM (0.764). The ICC between BIA-Segal and DXA for BF\% (0.471), and between SKF and DXA for FFM (0.611) represented moderate reproducibility. The ICC obtained between BIA-man and DXA for BF\% (0.179) and FFM (0.340), and between SKF and DXA for BF\% (0.167) was indicative of poor reproducibility (Table 2 ).

Table 1. Percentage body fat, fat mass, and fat-free mass assessed by different body composition methods

\begin{tabular}{lccc}
\hline Method & \% Body fat & Fat mass $\mathbf{( k g )}$ & Fat-free mass $\mathbf{( k g )}$ \\
\hline DXA & $44.6 \pm 5.5$ & $33.6 \pm 8.0$ & $43.6 \pm 4.3$ \\
BIA-manufacturer & $37.8 \pm 4.4^{*}$ & $30.4 \pm 6.4$ & $49.3 \pm 5.2^{*}$ \\
BIA-Segal & $43.2 \pm 3.6$ & $34.6 \pm 6.6$ & $45.1 \pm 4.6$ \\
BIA-Gray & $44.7 \pm 5.8$ & $35.9 \pm 7.8$ & $43.8 \pm 5.2$ \\
SKF & $42.3 \pm 3.6$ & $33.7 \pm 5.4$ & $45.9 \pm 6.6$ \\
\hline
\end{tabular}

Values are mean \pm standard deviation. DXA: dual X-ray absorptiometry; BIA: bioelectrical impedance analysis; SKF: skinfold thickness.

${ }^{*} \mathrm{P}<0.05$.

\section{DISCUSSION}

The main finding of this study was that, in a group of overweight and obese Brazilian women, all body composition assessments provided good relative agreement with DXA, as indicated by high correlation coefficients, except for BF\% assessed by SKF. However, in absolute terms, all methods were associated with wide limits of agreement. Compared with DXA, BIA-man substantially underestimated $\mathrm{BF} \%$ and overestimated FFM, whereas BIA-Segal and BIA-Gray as well as SKF methods provided good absolute agreement for all body components assessed. In addition, BF\%, FM, and FFM measurements obtained by BIA-Gray provided higher ICC indicating good reproducibility between BIAGray and DXA methods.

For the BIA method examined in the present study using the three different equations, BIA-man, BIA-Segal and BIA-Gray, correlations with DXA for $\mathrm{BF} \%, \mathrm{FM}$, and FFM were generally good. This finding is comparable to previous studies, which have reported a high correlation between DXA and BIA in overweight or obese populations (22-24). However, although high correlation coefficients indicate good relative agreement, correlation analysis alone is not sufficient to verify the degree of coincidence among the methods $(20)$.

Table 2. Comparison of methods of body composition with DXA

\begin{tabular}{|c|c|c|c|c|c|c|}
\hline \multirow[b]{2}{*}{ Comparison } & \multicolumn{2}{|c|}{ Regression analysis } & \multicolumn{2}{|c|}{ Bland and Altman } & \multicolumn{2}{|c|}{ Intra-class correlation coefficient } \\
\hline & $r^{2}$ & p-Value & $\begin{array}{l}\text { Mean bias } \pm \\
\text { SD of bias }\end{array}$ & $\begin{array}{c}\text { 95\% limits of } \\
\text { agreement }\end{array}$ & $\mathbf{r}$ & p-Value \\
\hline \multicolumn{7}{|c|}{ BIA-manufactory vs. DXA } \\
\hline$\%$ body fat & 0.751 & $<0.001$ & $-6.8 \pm 3.7$ & -14.0 to 0.3 & 0.179 & 0.149 \\
\hline Fat mass (kg) & 0.899 & $<0.001$ & $-3.1 \pm 3.6$ & -10.3 to 3.8 & 0.791 & $<0.001$ \\
\hline Free-fat mass $(\mathrm{kg})$ & 0.841 & $<0.001$ & $5.7 \pm 2.8$ & 0.2 to 11.3 & 0.340 & 0.022 \\
\hline \multicolumn{7}{|l|}{ BIA-Segal vs. DXA } \\
\hline$\%$ body fat & 0.802 & $<0.001$ & $-1.5 \pm 1.5$ & -8.7 to 5.8 & 0.471 & 0.002 \\
\hline Fat mass (kg) & 0.920 & $<0.001$ & $1.0 \pm 3.2$ & -5.3 to 7.3 & 0.897 & $<0.001$ \\
\hline Free-fat mass $(\mathrm{kg})$ & 0.833 & $<0.001$ & $1.5 \pm 2.6$ & -3.6 to 6.6 & 0.784 & $<0.001$ \\
\hline \multicolumn{7}{|l|}{ BIA-Gray vs. DXA } \\
\hline$\%$ body fat & 0.700 & $<0.001$ & $0.05 \pm 4.4$ & -8.5 to 8.6 & 0.706 & $<0.001$ \\
\hline Fat mass $(\mathrm{kg})$ & 0.867 & $<0.001$ & $2.3 \pm 4.1$ & -5.7 to 10.3 & 0.833 & $<0.001$ \\
\hline Free-fat mass $(\mathrm{kg})$ & 0.825 & $<0.001$ & $0.2 \pm 2.9$ & -5.5 to 5.9 & 0.812 & $<0.001$ \\
\hline \multicolumn{7}{|l|}{ SKF vs. DXA } \\
\hline$\%$ body fat & 0.248 & 0.158 & $-2.3 \pm 5.8$ & -17.3 to 9.1 & 0.167 & 0.166 \\
\hline Fat mass (kg) & 0.819 & $<0.001$ & $0.09 \pm 4.7$ & -9.2 to 9.4 & 0.764 & $<0.001$ \\
\hline Free-fat mass $(\mathrm{kg})$ & 0.746 & $<0.001$ & $2.4 \pm 4.4$ & -6.3 to 11.12 & 0.611 & $<0.001$ \\
\hline
\end{tabular}

DXA: dual X-ray absorptiometry; BIA: bioelectrical impedance analysis; SKF: skinfold thickness. 


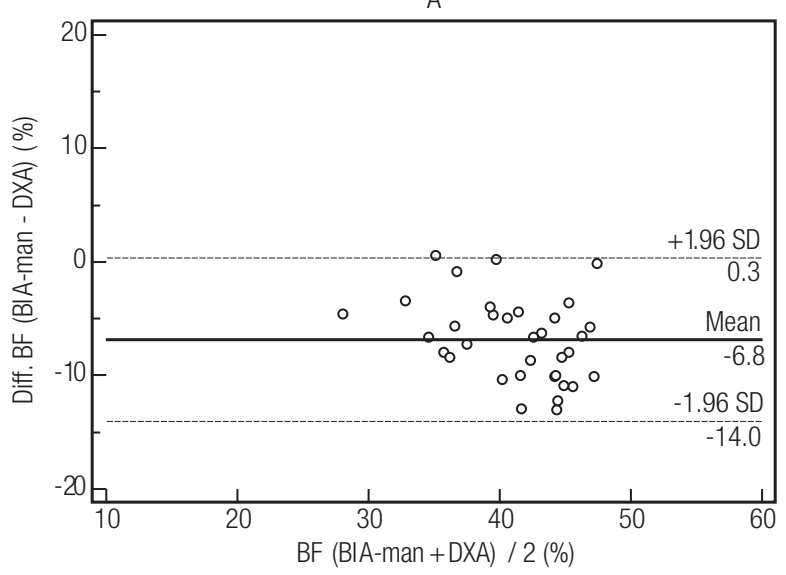

B

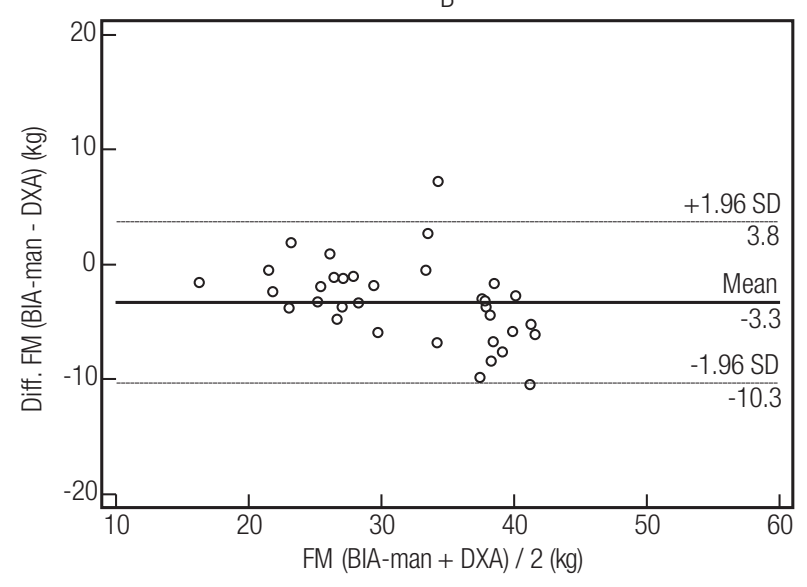

C

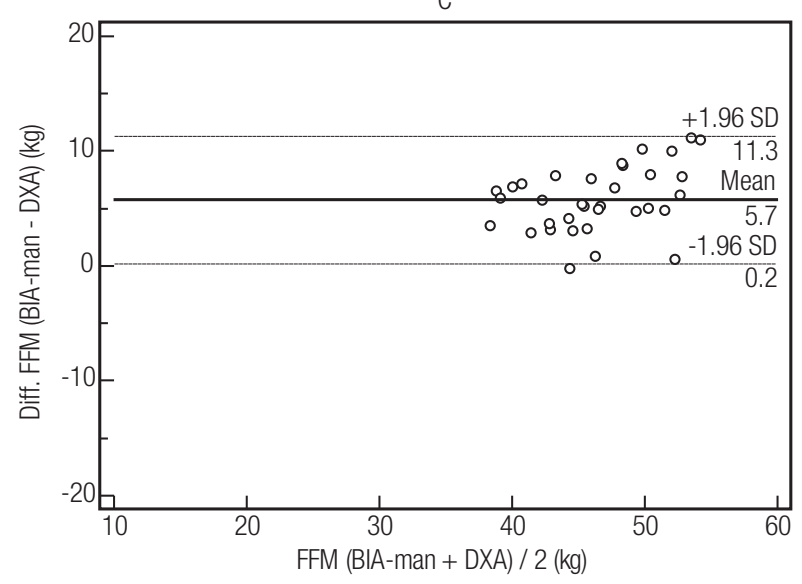

Figure 1. Bland-Altman plots showing the limits of agreement between (A) percentage body fat (BF\%), (B) fat mass (FM), and (C) fat-free mass (FFM) as determined by bioelectrical impedance analysis (BIA) using the equation provided by the manufacturer of the instrument (BIA-man) and dual energy $X$-ray absorptiometry (DXA). The center line represents the mean differences between the two methods, and the other two lines represent two SDs from the mean.

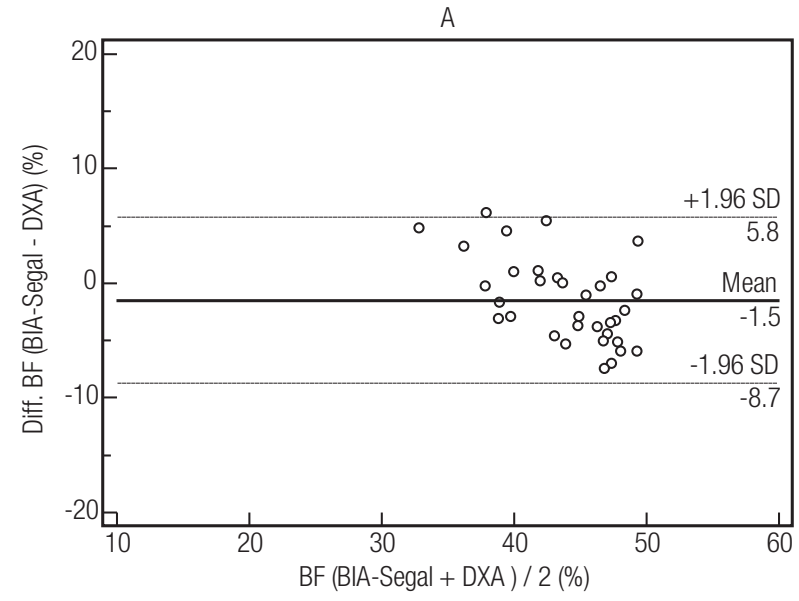

B

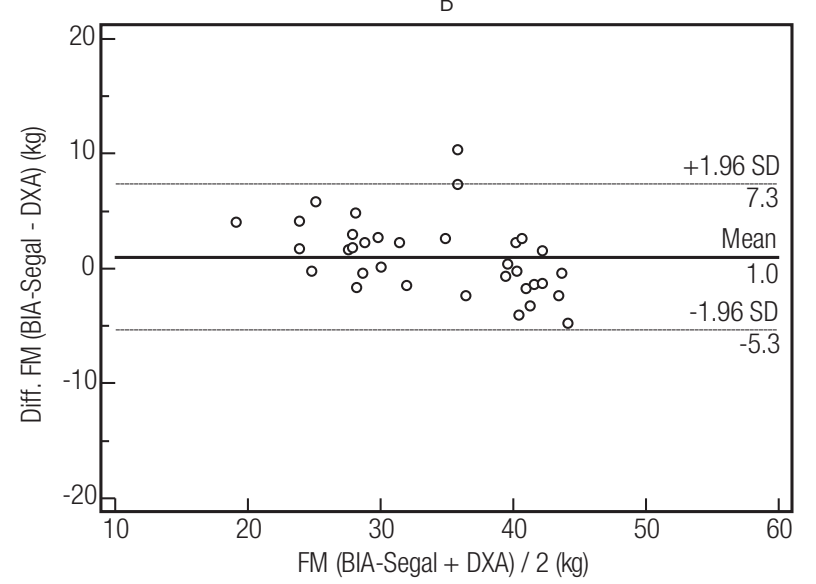

C

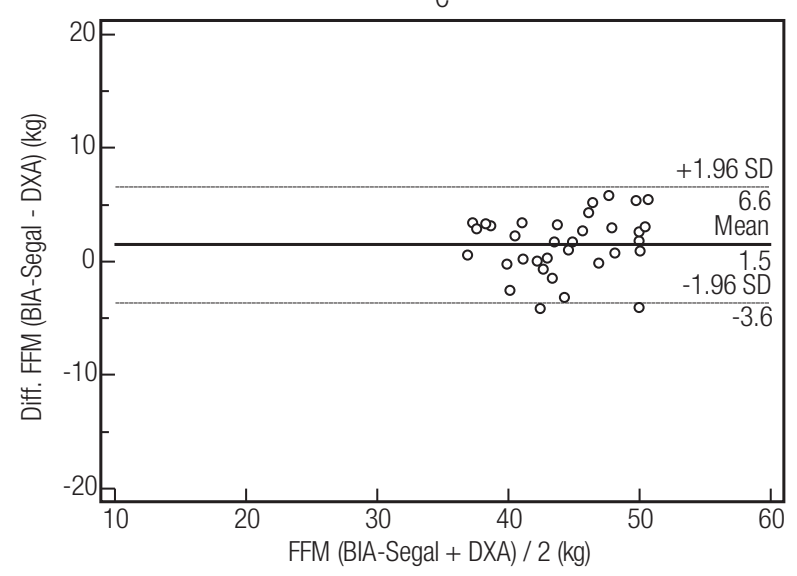

Figure 2. Bland-Altman plots showing the limits of agreement between $(\mathbf{A})$ percentage body fat (BF\%), (B) fat mass (FM), and (C) fat-free mass (FFM) as determined by bioelectrical impedance analysis (BIA) using the obesespecific equation of Segal (BIA-Segal) and dual energy X-ray absorptiometry (DXA). The center line represents the mean differences between the two methods, and the other two lines represent two SDs from the mean. 
A

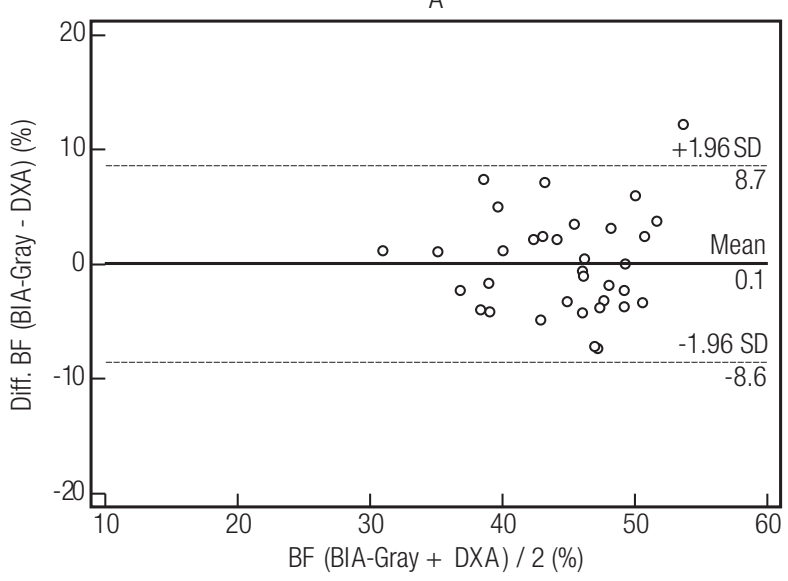

B

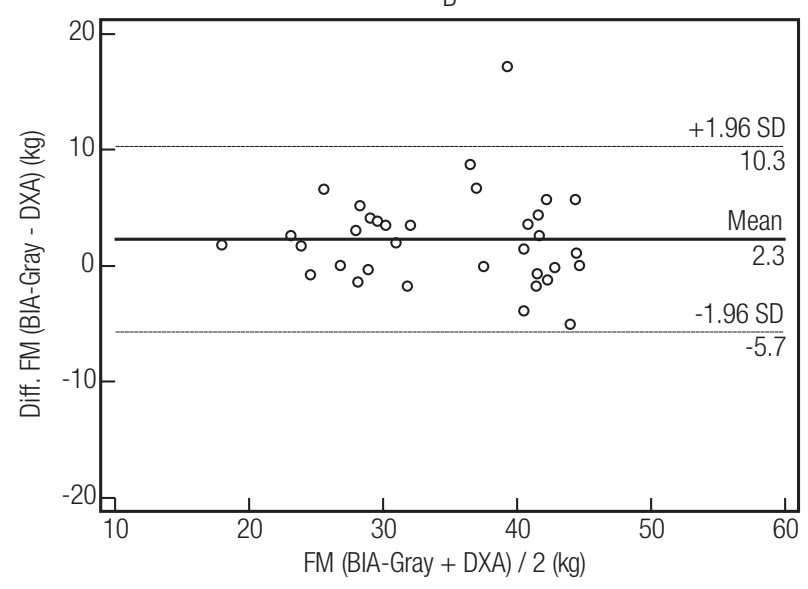

c

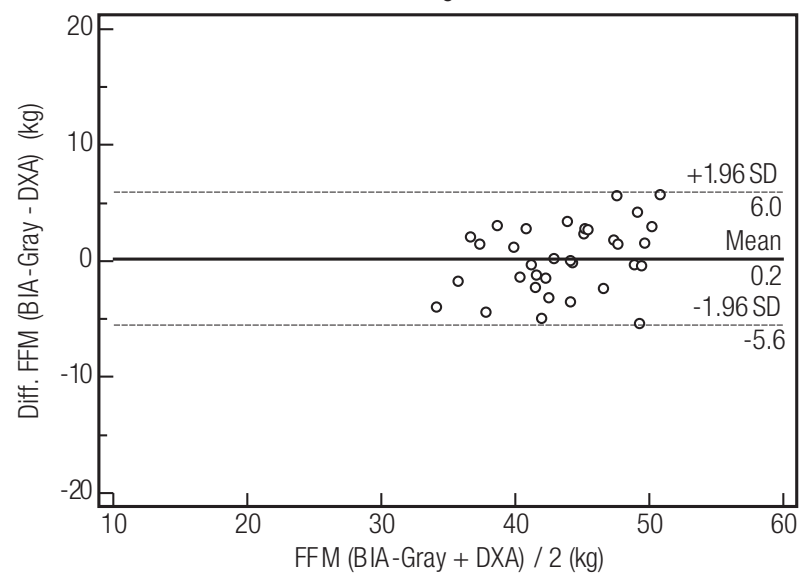

Figure 3. Bland-Altman plots showing the limits of agreement between $(\mathbf{A})$ percentage body fat (BF\%), (B) fat mass (FM), and (C) fat-free mass (FFM) as determined by bioelectrical impedance analysis (BIA) using the obesespecific equation of Gray (BIA-Gray) and dual energy X-ray absorptiometry (DXA). The center line represents the mean differences between the two methods, and the other two lines represent two SDs from the mean.
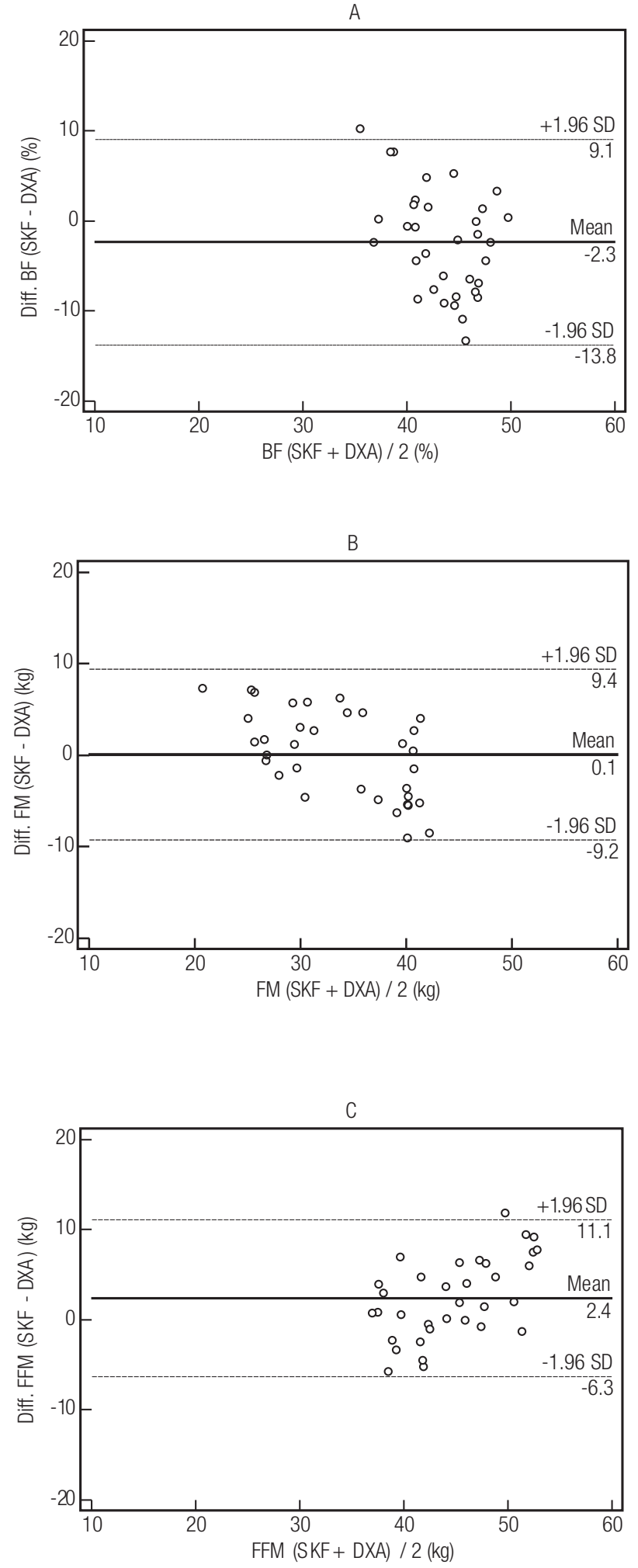

Figure 4. Bland-Altman plots showing the limits of agreement between $(\mathbf{A})$ percentage body fat (BF\%), (B) fat mass (FM), and (C) fat-free mass (FFM) as determined by skinfold thickness (SKF) and dual energy $X$-ray absorptiometry (DXA). The center line represents the mean differences between the two methods, and the other two lines represent two SDs from the mean. 
Although BIA-man demonstrated a good relative agreement with DXA, it provided the poorest absolute levels of agreement with a large bias in underestimating body fat content $(\sim 7 \%)$ and overestimating FFM $(\sim 6 \mathrm{~kg})$. This finding is consistent with the results of previous studies $(22,25-27)$ which indicated that BIAman results significantly underestimated body fat content in overweight and obese women $(22,26,27)$, and non-obese subjects (25) when compared with DXA.

Results of the current study and of the three previous studies $(22,26,27)$ indicate that BIA-man provides a poor level of absolute agreement with DXA, suggesting that BIA-man may not be suitable for the measurement of body composition in overweight and obese women in clinical research as well as clinical facilities.

Thus, in a population of obese people, equations developed to estimate lean mass in the healthy population through BIA are probably not valid to assess body fat by subtracting estimated lean mass from total body weight (26). In fact, whenever the manufacturer's equations are used, BIA may overestimate lean tissue and underestimate fat in obese subjects $(11,13,28,29)$.

The current study employed two obesity-specific BIA analysis equations because studies have shown that the predictive accuracy for BIA method may be improved using obesity-specific equations to estimate an obese population's body composition. The Gray obesityspecific equation validated the Segal equation over a wide range of body fat values $(11,13)$.

We found that the bias for the absolute differences between DXA and BIA-Segal or BIA-Gray were small. These findings of good absolute agreement between BIA-Segal or BIA-Gray and DXA, taken together with the good relative agreement among methods, indicate that BIA using either obesity-specific equations such as Segal (13) or Gray equation (11) is a reliable method for assessing body fat and free-fat mass at the group level in overweight/obese populations. However, the wide limits of agreement confine the utility of this technique to any accurate determination of an individual body composition, and its use, therefore, seems limited in clinical facilities. Additionally, these wide limits of agreement are in accordance with previous reports using obesity-specific equations (24).

The most widely applied method for calculating total body fat from measured SKF in current use was developed by Durnin and Womersley (15). Body density obtained by Durnin and Womersley (15) is derived from a spectrum of lean to moderately obese subjects, and are expected to lose precision in severely obese subjects with $\mathrm{BF} \%$ far higher than their validation population means (30). The results of the current study show good relative agreement between SKF and DXA for the assessment of FM, as well as good absolute agreement and good reproducibility. Also, the mean difference between these methods was not significant. Thus, for FM, it is reasonable to consider the SKF method very useful to assess overweight and obese women, and as the most simple and inexpensive method. In contrast, no significant correlation was found between SKF and DXA for $\mathrm{BF} \%$ assessment. Despite the good absolute agreement, there were large biases between SKF and DXA measurements, along with poor degree of reproducibility obtained by ICC for BF\%.

Usually total body fat estimations are expressed as percentage body weight. However, a problem in this approach is that the relationship between total body fat and body weight has a nonzero intercept. The result is that a curvilinear relationship exists between total body fat, expressed as a percent of body weight and body weight or BMI (31). Indeed, the complex relationship between percentage of fat and body weight can result in some indefinite situations.

A severely obese patient could lose a relatively large amount of weight and yet have a relatively small change in percentage of fat. The SKF method cannot be recommended for overweight or obese individuals although it can be used to validate the estimation of $\mathrm{BF} \%$ for diverse healthy age and ethnic groups, because increasing levels of body fat leads to subcutaneous total body fat proportional changes, thereby affecting the relationship between the sum of skinfolds and relative body fat (14).

Finally, according to our results, BIA-Segal as well as BIA-Gray equations provided the most accurate and precise estimations of $\mathrm{BF} \%, \mathrm{FM}$, and FFM in comparison to DXA in overweight and obese Brazilian women. However, due to broad limits of agreement, we can only recommend these equations to groups of populations, not of individuals.

Acknowledgments: the authors gratefully acknowledge Mrs. Rosângela A. M. Noé for statistical assistance.

Disclosure: no potential conflict of interest relevant to this article was reported.

\section{REFERENCES}

1. World Health Organization. Obesity: preventing and managing the global epidemic. Report of a WHO consultation. World Health Organ Tech Rep Ser. 2000;894:i-xii, 1-253. 
2. Mokdad AH, Bowman BA, Ford ES, Vinicor F, Marks JS, Koplan JP. The continuing epidemics of obesity and diabetes in the United States. JAMA. 2001;286(10):1195-200.

3. Okosun IS, Chandra KM, Choi S, Christman J, Dever GE, Prewitt TE. Hypertension and type 2 diabetes comorbidity in adults in the United States: risk of overall and regional adiposity. Obes Res. 2001;9(1):1-9.

4. Rader DJ. Effect of insulin resistance, dyslipidemia, and intra-abdominal adiposity on the development of cardiovascular disease and diabetes mellitus. Am J Med. 2007;120(3 Suppl 1):S12-8.

5. Ritz P, Salle A, Audran M, Rohmer V. Comparison of different methods to assess body composition of weight loss in obese and diabetic patients. Diabetes Res Clin Pract. 2007;77(3):405-11.

6. Prior BM, Cureton KJ, Modlesky CM, Evans EM, Sloniger MA, Saunders $\mathrm{M}$, et al. In vivo validation of whole body composition estimates from dual-energy X-ray absorptiometry. J Appl Physiol. 1997;83(2):623-30.

7. Thomson R, Brinkworth GD, Buckley JD, Noakes M, Clifton PM. Good agreement between bioelectrical impedance and dualenergy X-ray absorptiometry for estimating changes in body composition during weight loss in overweight young women. Clin Nutr. 2007;26(6):771-7.

8. King S, Wilson J, Kotsimbos T, Bailey M, Nyulasi I. Body composition assessment in adults with cystic fibrosis: comparison of dual-energy X-ray absorptiometry with skinfolds and bioelectrical impedance analysis. Nutrition. 2005;21(11-12):1087-94.

9. Lukaski HC. Methods for the assessment of human body composition: traditional and new. Am J Clin Nutr. 1987;46(4):537-56.

10. Kyle UG, Bosaeus I, De Lorenzo AD, Deurenberg P, Elia M, Gomez $\mathrm{JM}$, et al. Bioelectrical impedance analysis - part I: review of principles and methods. Clin Nutr. 2004;23(5):1226-43.

11. Gray DS, Bray GA, Gemayel N, Kaplan K. Effect of obesity on bioelectrical impedance. Am J Clin Nutr. 1989;50(2):255-60.

12. Jakicic JM, Wing RR, Lang W. Bioelectrical impedance analysis to assess body composition in obese adult women: the effect of ethnicity. Int J Obes Relat Metab Disord. 1998;22(3):243-9.

13. Segal KR, Van Loan M, Fitzgerald PI, Hodgdon JA, Van Itallie TB. Lean body mass estimation by bioelectrical impedance analysis: a four-site cross-validation study. Am J Clin Nutr. 1988;47(1):7-14.

14. Stolarczyk LM, Heyward VH. Assessing body composition of adults with diabetes. Diabetes TechnolTher. 1999 Fall;1(3):289-96.

15. Durnin JV, Womersley J. Body fat assessed from total body density and its estimation from skinfold thickness: measurements on 481 men and women aged from 16 to 72 years. $\mathrm{Br} \mathrm{J}$ Nutr. 1974;32(1):77-97.

16. Kamimura MA, Avesani CM, Cendoroglo M, Canziani ME, Draibe SA, Cuppari L. Comparison of skinfold thicknesses and bioelectrical impedance analysis with dual-energy $\mathrm{X}$-ray absorptiometry for the assessment of body fat in patients on long-term haemodialysis therapy. Nephrol Dial Transplant. 2003;18(1):101-5.
17. Bottaro MM HV, Lindolfo JB. Cross-validation of bioimpedance (BI) equations for Brazilian women using dual-energy x-ray absorptiometry (DXA) [abstract]. Med Sci Sports Exerc. 1999;31:S200

18. Oliveira FL, Taddei JA, Escrivao MA, Cobayashi F, Barros ME, Vitolo MR, et al. Accuracy of obesity diagnosis in Brazilian adolescents: comparison of Cole et al and Must et al criteria with DXA percentage of fat mass. Nutr Hosp. 2006;21(4):484-90.

19. Siri WE. Body composition from fluid spaces and density: analysis of methods. 1961. Nutrition. 1993;9(5):480-91; discussion, 92.

20. Bland JM, Altman DG. Statistical methods for assessing agreement between two methods of clinical measurement. Lancet. 1986;1(8476):307-10.

21. Bartko JJ, Carpenter WT Jr. On the methods and theory of reliability. J Nerv Ment Dis. 1976;163(5):307-17.

22. Andreoli A, Melchiorri G, De Lorenzo A, Caruso I, Sinibaldi Salimei $P$, Guerrisi M. Bioelectrical impedance measures in different position and vs dual-energy X-ray absorptiometry (DXA). J Sports Med Phys Fitness. 2002;42(2):186-9.

23. Frisard MI, Greenway FL, Delany JP. Comparison of methods to assess body composition changes during a period of weight loss. Obes Res. 2005;13(5):845-54.

24. Pateyjohns IR, Brinkworth GD, Buckley JD, Noakes M, Clifton PM. Comparison of three bioelectrical impedance methods with DXA in overweight and obese men. Obesity (Silver Spring). 2006;14(11):2064-70.

25. Bolanowski M, Nilsson BE. Assessment of human body composition using dual-energy $x$-ray absorptiometry and bioelectrical impedance analysis. Med Sci Monit. 2001;7(5):1029-33.

26. Panotopoulos G, Ruiz JC, Guy-Grand B, Basdevant A. Dual x-ray absorptiometry, bioelectrical impedance, and near infrared interactance in obese women. Med Sci Sports Exerc. 2001;33(4):665-70.

27. Sun G, French CR, Martin GR, Younghusband B, Green RC, Xie $Y G$, et al. Comparison of multifrequency bioelectrical impedance analysis with dual-energy $\mathrm{X}$-ray absorptiometry for assessment of percentage body fat in a large, healthy population. Am J Clin Nutr. 2005;81(1):74-8.

28. Deurenberg P, van der Kooy K, Leenen R, Weststrate JA, Seidell JC. Sex and age specific prediction formulas for estimating body composition from bioelectrical impedance: a cross-validation study. Int J Obes. 1991;15(1):17-25.

29. Ellis KJ. Human body composition: in vivo methods. Physiol Rev. 2000;80(2):649-80.

30. Teran JC, Sparks KE, Quinn LM, Fernandez BS, Krey SH, Steffee WP. Percent body fat in obese white females predicted by anthropometric measurements. Am J Clin Nutr. 1991;53(1):7-13.

31. Webster JD, Hesp R, Garrow JS. The composition of excess weight in obese women estimated by body density, total body water and total body potassium. Hum Nutr Clin Nutr. 1984;38(4): 299-306. 